\title{
مؤسسة المخزن في تاريخ المغرب
}

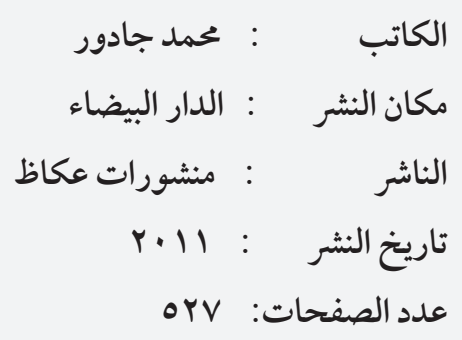

يحاول المؤرخ المغربي محمد جادور في استنطاق البنية الرمزية لنظيمة المخزن وخلخلة هذه

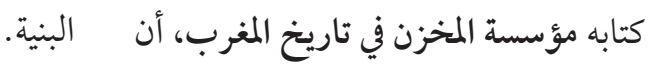

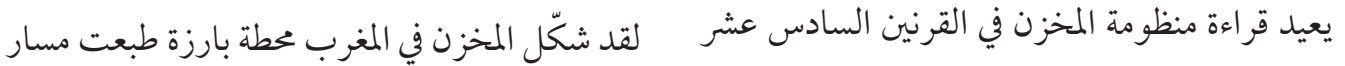

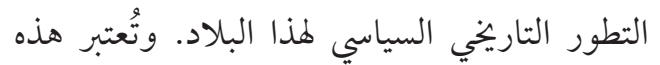

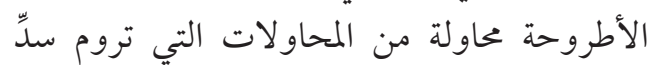
والسابع عشر، عبر قراءة مقارنة لتجربتين متتاليتين،

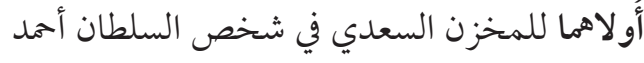

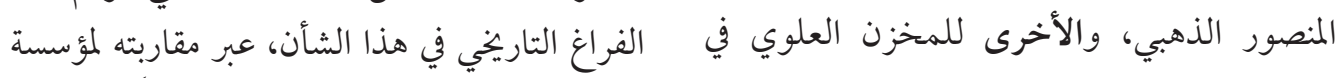

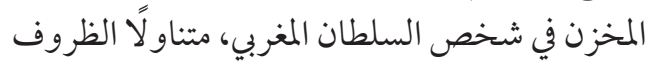

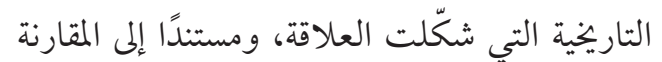

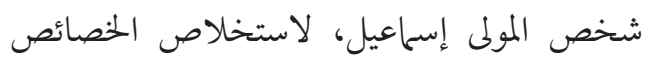

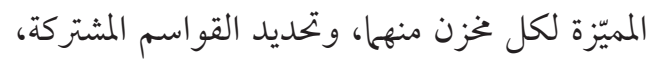

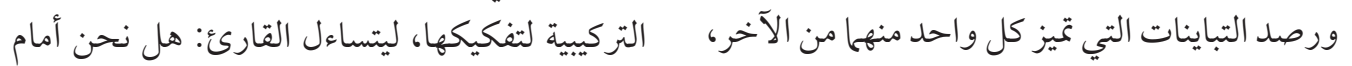

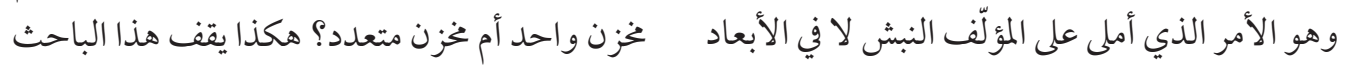

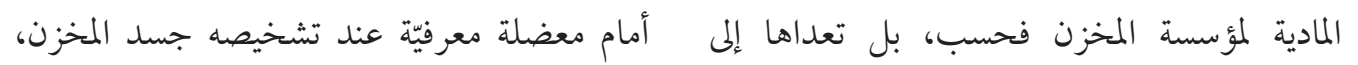


المعبّر عن دلالة المخزن، فإنهّا تتخذ - في بُعديها المادي

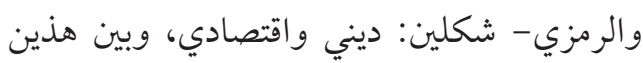

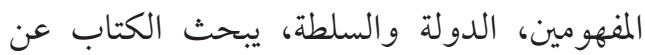
المخزن الذي شكّل لغنزًا سياسيًا مركّبًا.

\section{المخزن، المؤسسة} وأشكال الحضور : القوة والرمز

لا مندوحة من القول إن من غير الممكن فهم المجم

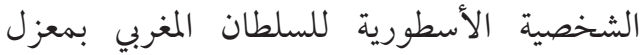

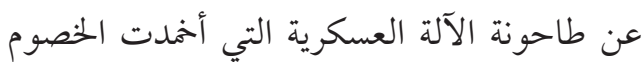
السياسيين، وتر افقها مع أسطرة دينيّة أخذت أشكالة الشكالًا

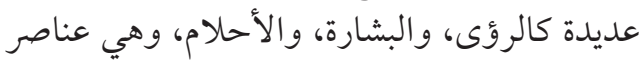
ثابتة تزكي شرعية الخلافة الدينية.

وعبر تحليل الثيولوجيا الدينية المغربيّة وعلاقة

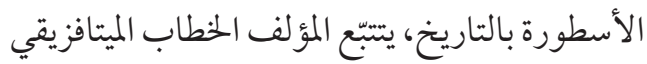

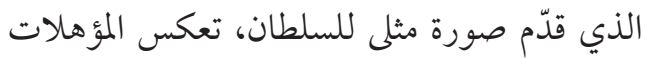

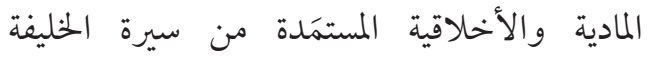

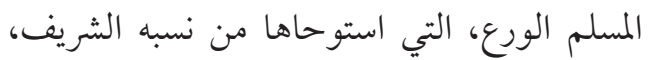

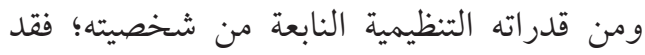

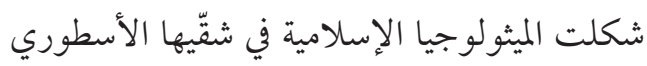

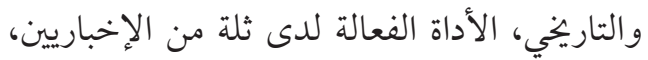

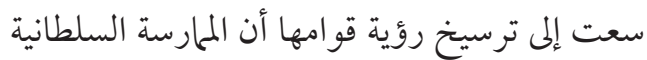

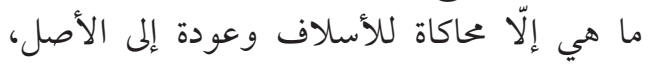

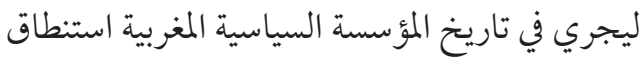

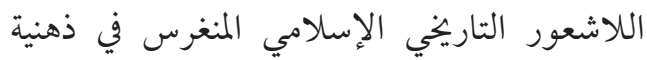
الإخباريين، وإقامة التماثل في الحاضر، حيث الإنافي معركة

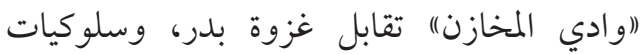
السلطان المغربي هي ذاتها سلوكيّات الخليفة الراشدي ترني

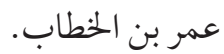

اتخذت إذًا الأسطوغرافية المحلية من البُعد الديني

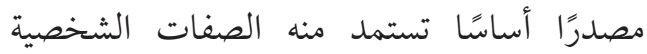
للسلطان، وتشكّل في آن إطارًا ثقافيتّا وسياسيَّا، به الهيه
تتعلق بالمادة التاريخية التي تؤرخ للسلطان المغربي، وهي ذات مسارب متعددة الأوجه وحاملة معانٍ

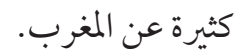

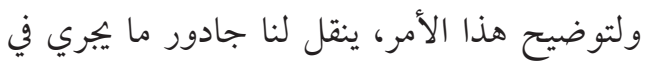

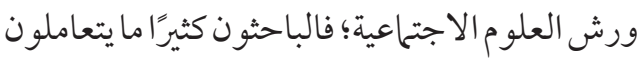

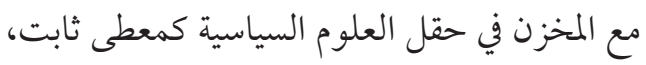

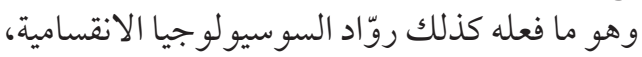

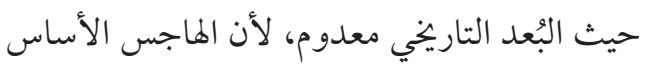

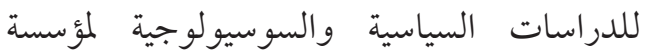
المخزن لا تخرج عن المعادلة التحليلية التي تختزله ولئه

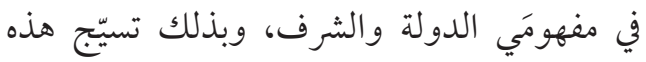

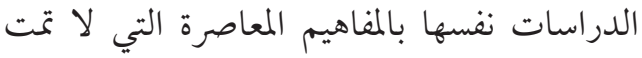
بأي صلة، لتجربة سياسية متجذرة في التاريخ - وفي التعاصي

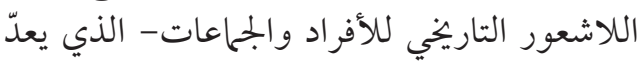
المصدر الوحيد للفهم والتوجيه.

عبر تأكيد المؤلف ضرورة فهم المخزن كمؤسسة

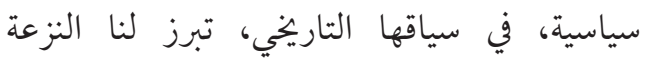

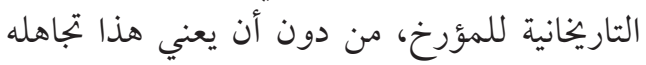

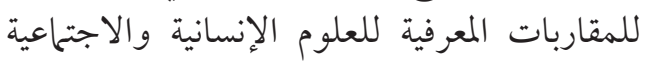
الرديفة، ليخلص إلى تسميته الجهاز تارة، والمنظومة الإنسانة والاجنية

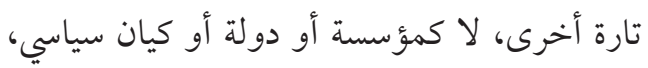

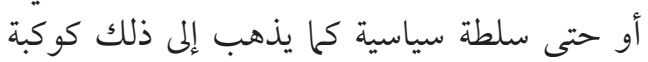
من المؤرخين، ليتمحور هذا العمل حول إنيال الشكال

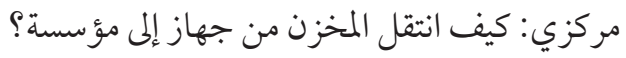

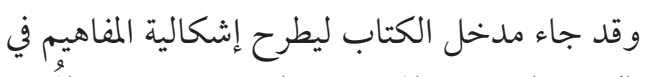

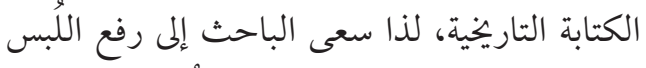

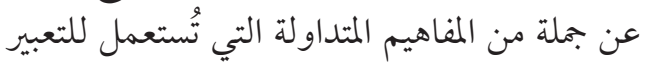

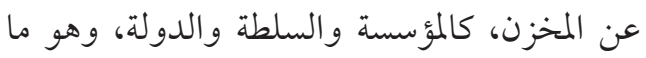

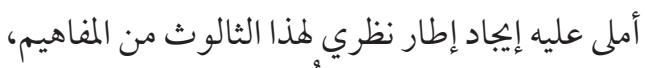

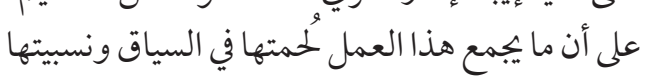

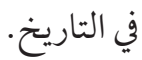

وفي رأي المؤلّف، فإن الدولة مفهوم زئبقي ونسبي تعود أصوله النظرية إلى التراث الأوروبي في شقيّيه الروماني والنهضوي. أمّا السلطة، وهي المفهوم الثاني الأوري فئه 
إلى سياسة العصا والجزرة. وفي هذا الإطار يميز

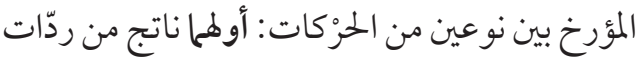

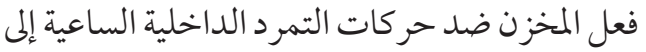
تركيع قياداتها، وتندرج ضمن معن ما يسميه محمد جادور

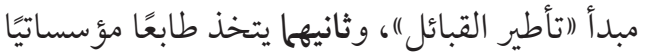

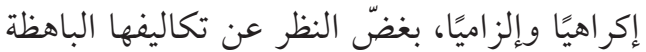

وقلة مردوديتها.

إن الهدف من (الحَرْكات)" إذًا، كما يقول الباحث، هو

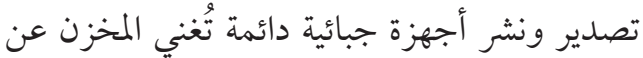

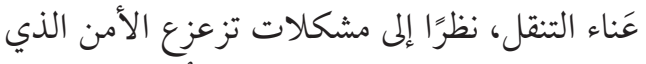

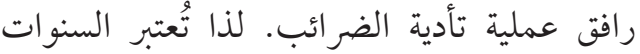

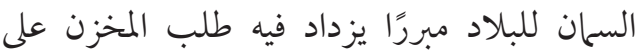

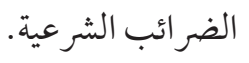

\section{أشكال الحضور الرمزي للمخزن}

تُعتبر الرمزية السياسية أحد المداخل الأساسية التي

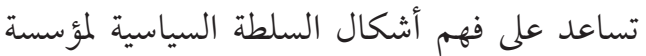

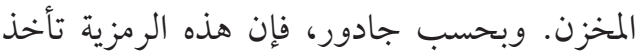
مظاهر عديدة: ثابتة ومتغيرة، مرئية ومجردة، ويمثّل

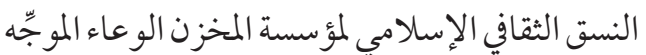
لها، وهي تتجلى في ظاهرة الاحتفالية (المراسيم)

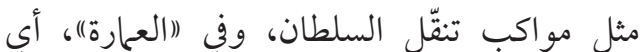

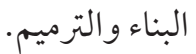

وتُعتبر الأعياد الدينية (الفطر والأضحى والمولد

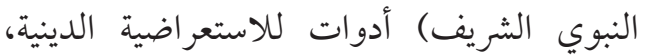

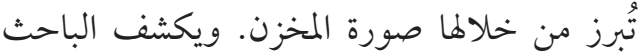
عن ثنائيات متناقضة تستوعبها الممارسة الخطابيّة

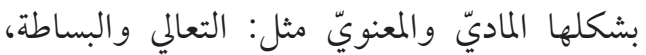
الهيبة والتواضع، الدِّين والسياسة، الفضاء الخاص للسلطان في مقابل الفضاء العام للرعايا.

وتؤثث النخبة الدينية إلى جانب كبار رجال بلاط المخزن الموكب السلطاني لإحياء الأعياد المقدسة التي الني التئي
تُسيّج مؤسسة المخزن، في حين أن البعد السياسي

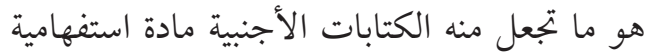

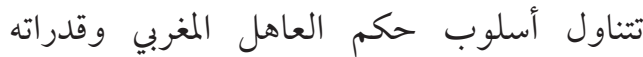
العسكرية. نحن إذًا أمام مرجعيتين نختلفتين لتشريح

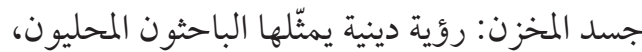

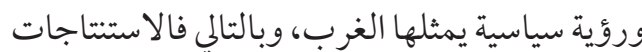
منغلقة بين تمجيد الذات وتعظيمها، وتبخيس للأنا من طرف (الآخر ) الأوروبي.

هكذا ترافق الحضور المادي للمخزن الذي تجسّد في

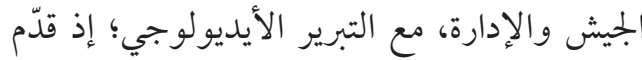

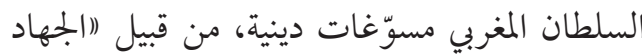
ضد النصارى)، إمّا لاسترجاع بلاد الأندلس وإمّا

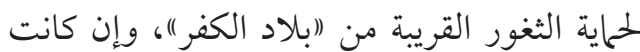

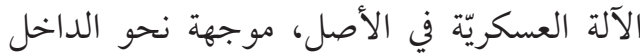

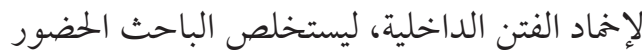

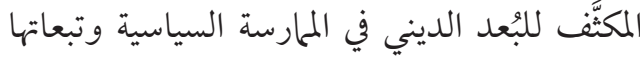

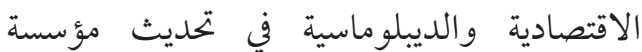

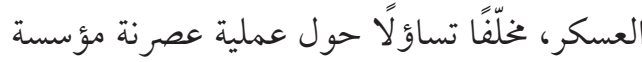

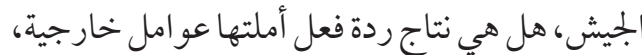
أم مسألة تعود إلى صيرورة بنيوية بجتمعية؟

لم يكن حضور مؤسسة المخزن من دون سند ديني؛

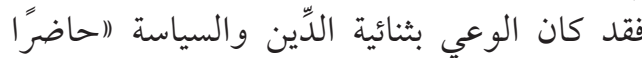

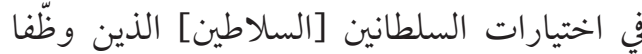

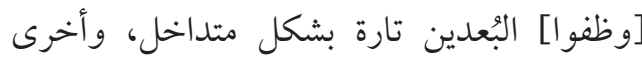

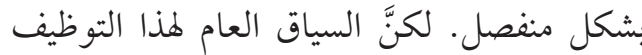

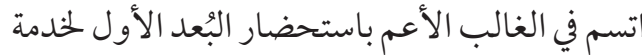

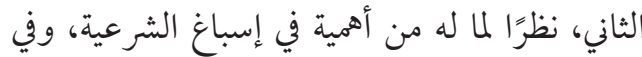
تدعيم السلطة وضمان استمرارها، إذ كان اكتمال

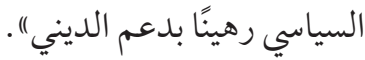

وتُشكّل (الحرُكة) (وهي حملة تأديبية يقوم بها السلطان

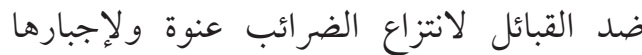

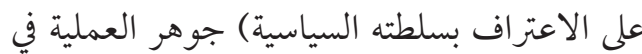

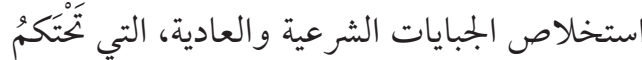




\section{الممارسات المخزنية: الآليات والأيعاد}

تناول الباحث الإشكال النظري القديم / الجديد

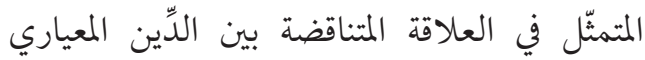

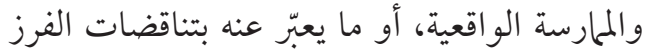

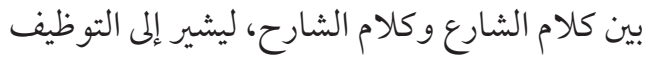

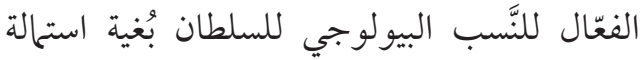

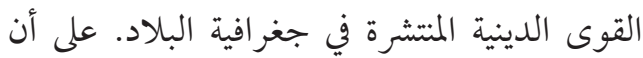

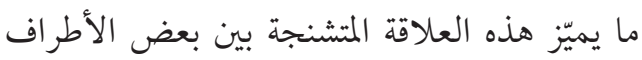

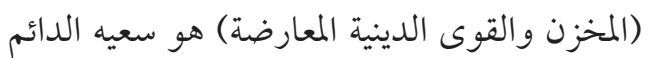

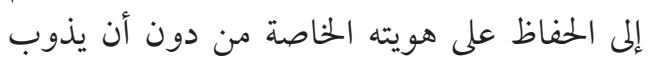

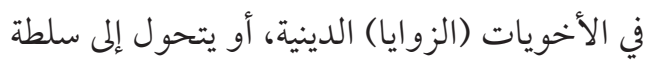

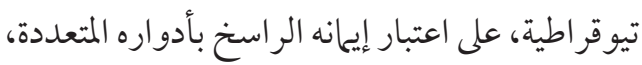
الدينية منها والدنيوية.

تختزل القاعدة اللغوية التالية: (إذا التقى ساكنان

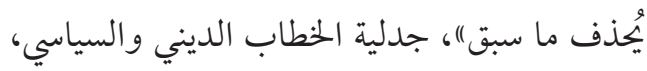

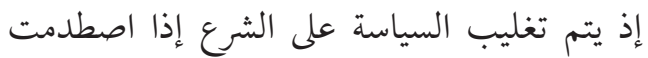

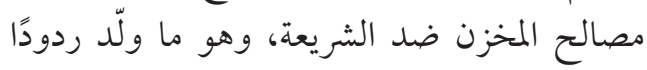

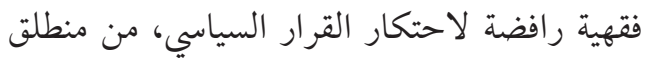

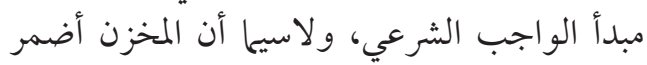

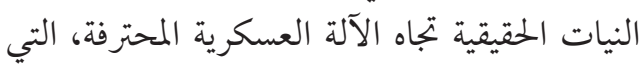

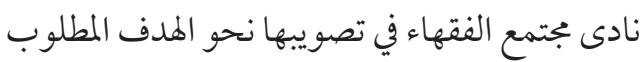

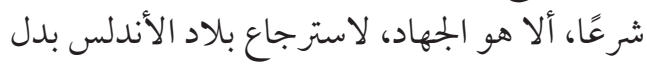

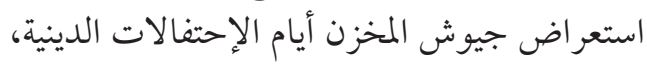
الأمر الذي يثير إشكالية إبستيمية تتمثّل في علاقة الإنة الإنية

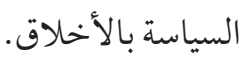

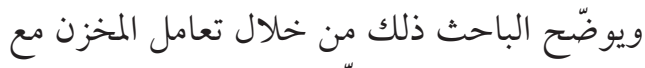

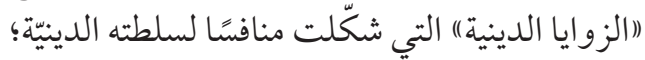

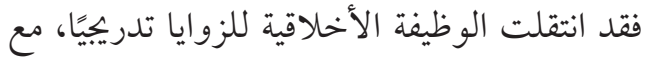

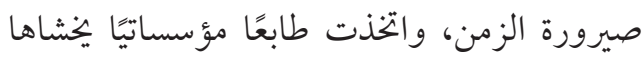

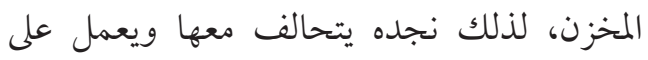
كسب ودها، ويحرص في الوقت نفسه نئه على احتو ائها بإعادة ترتيبها من الداخل عن طريق كسر شوكة التشن
هي تعبير استعر اضيّ لأبهة السلطان وعظمته، وقوة

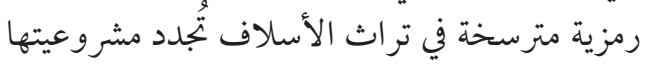

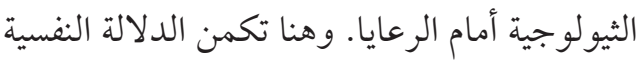

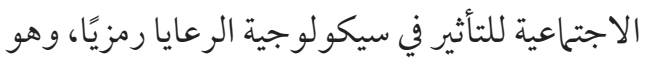

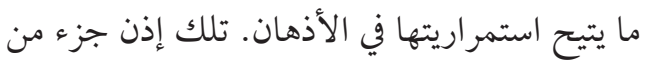

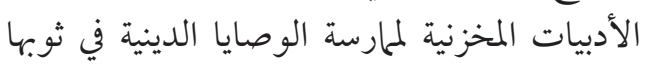

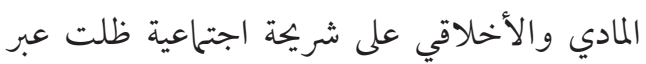
السنين تحت أعين سلاطين المخزن

ويركّز المؤلف على فضيلة الكرم بوصفها سلطة مادية

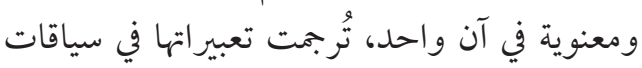

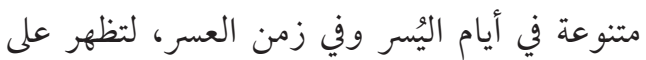

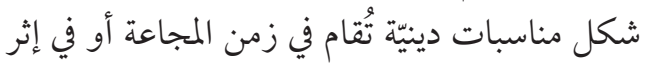

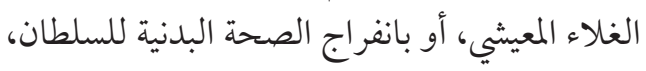

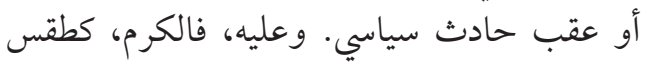
مناسباتي ولخظوي، محكوم بالزمان والمكان.

ونبّه الباحث، في استنطاقه أبعاد الكرم بوصفه المبه

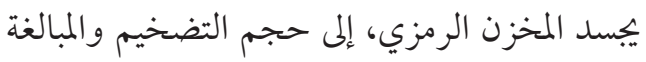

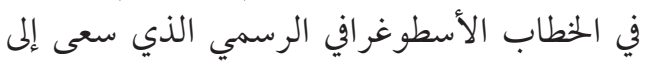

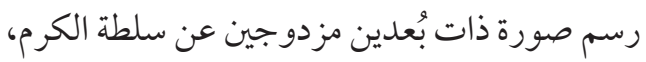

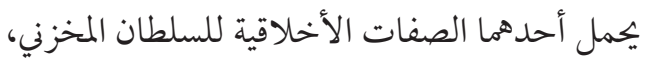

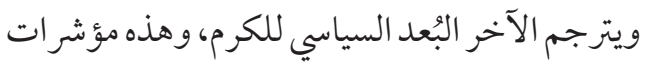

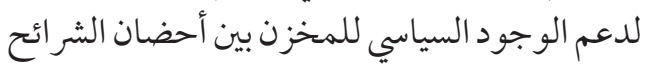

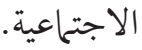

تمثّل الدبلوماسية شكلًا آخر للحضور الرمزي

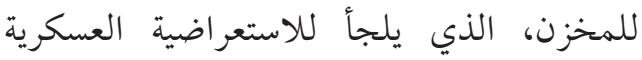

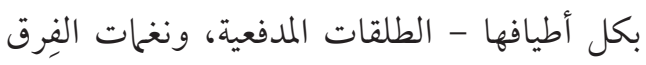

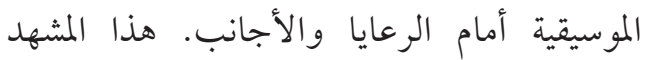

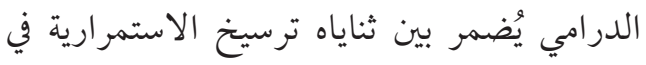
الأذهان والانبهار بعظمته وضخامة آلياته، وهو تئن

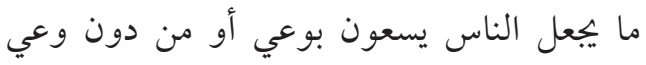

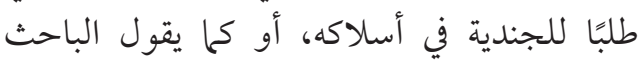
التسليم بتفوقه الدائم، وبغرض ونية إبهار الأغيار الأوروبيين وإذهالهم. 
اعتبار أن توزيعهم يتم على أساس معايير محدّدة

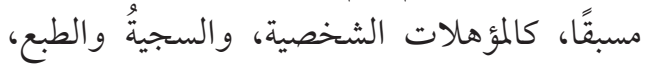

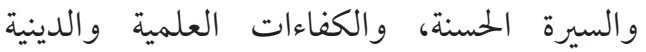

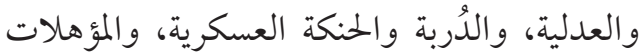

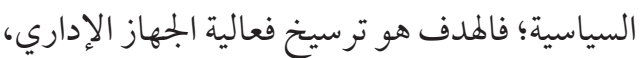

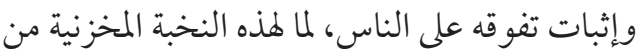
سلطات و اسعة: مالية، وعسكرية، وقضائية. هذا التنوّع الشديد هو الذي سبّب تعدد المنظورات

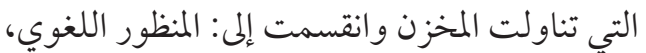

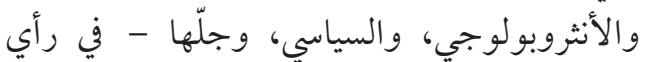

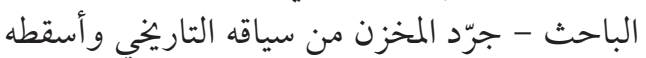

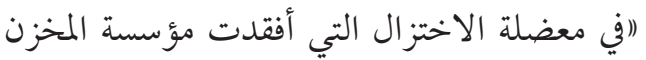

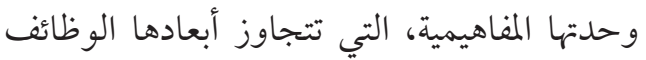

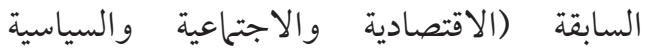

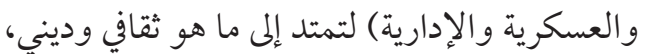
و إلى كل مجال يتداخل فيه حضورها ماديًا ورمزيًا... مما يعني أنها أهملت في تحليليلاتها فيه البعد التاريخي لمؤسسة المخزن، التي نمت في رحم مدى زمني طويل

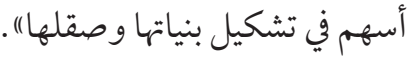

ومن المجازفة مقاربة مؤسسة المخزن بالمفهوم الأوروبي للدولة، كما ذهب إلى ذلك الباحث، وهوبه ما يجعلنا نهتدي إلى إجابة قطعية مفادها أن المخز لإدي دهن

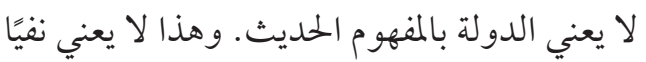

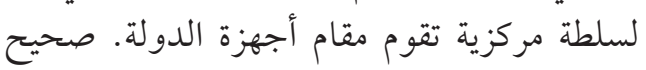
أن عناصر التشابه بين المخزن والدولة الوطنية

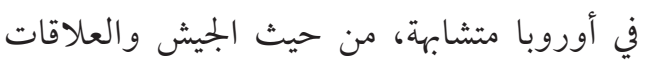

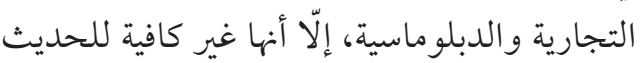
عن الدولة في مغرب القرنين السادس عشر و السابع

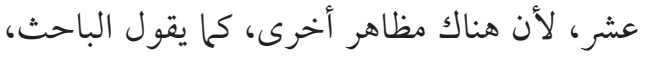

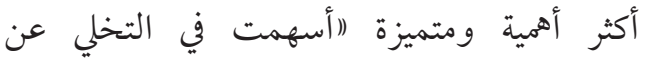
الشعور بالو لاء للأسرة وللجماعة وللتنظيم الديني لفائدة الدولة)، في الوقت الذي بقي في فيه المغرب ولتب

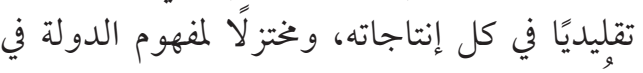
الأسرة الحاكمة.
زعائها والتأليب بينهم، والعمل على توريطها من

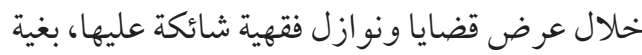
إزالة صفات التقديس والتعظيم عنها، وبالتالي تبديد الشعور الديني لدى المريدين والأتباع.

\section{منظومة المخزن: المضامين والدلالات}

وتو صل الباحث إلى مطاطية مفهوم المخزن، وما يثيره من جدل نظري، ويميز بين ثلاثة اتجاهات نظرية

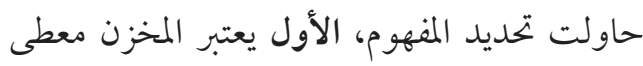
بديهيًا يجب التسليم به (المؤرخ)، والثاني أنه بنية

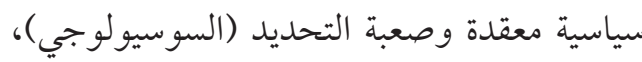

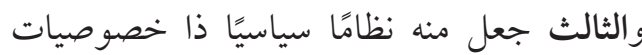

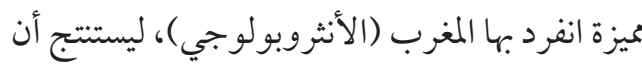
الاتجاهات النظرية الثلاثة، بالرغم من تعدد أدواتها

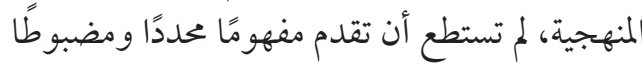
لمؤسسة المخزن.

وفي إطار مقاربة المؤلف للمفهوم، يذكّر بزمن ولادة

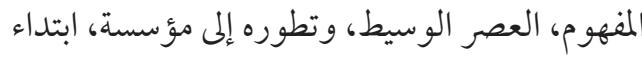

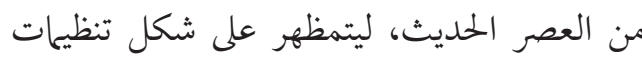

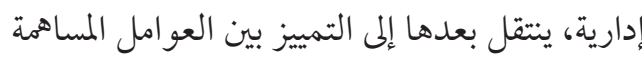

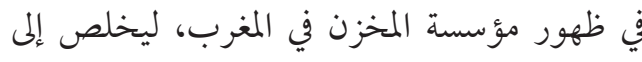

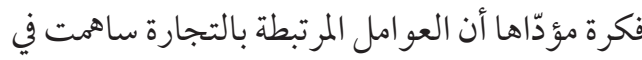

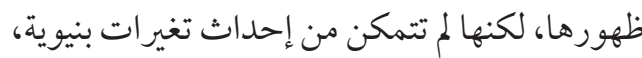

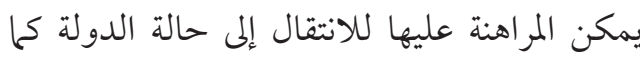

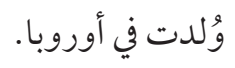
وفي رأي محمد جادور أن خصوصيّة المخزن في

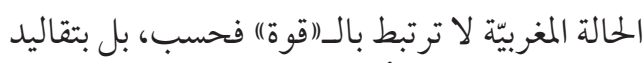

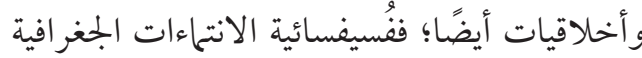
والأسرية التي ينحدر منها خدام المخزن (العنصر

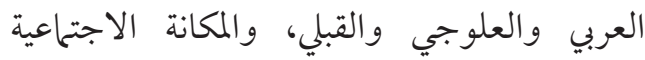

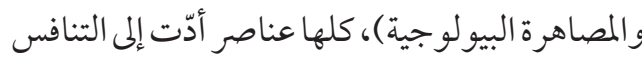

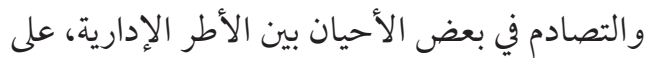


وملازمة السرّية والتكتم، كما نهج أساليب من قبيل

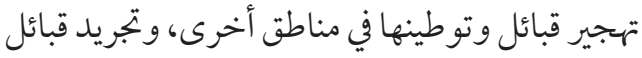

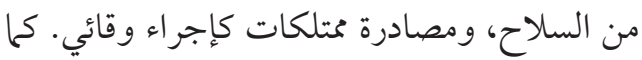

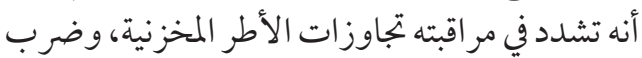

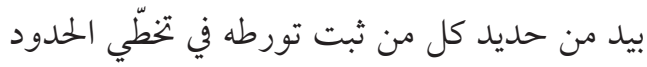
المرسومة، وكانت عيونه وآذانه بالمر صاد لتبتبّع أخبار الآخرين وأسرارهم وكشفها.

أمّا على الصعيد الثالث، فتعكس آليات الحزم التي الثي

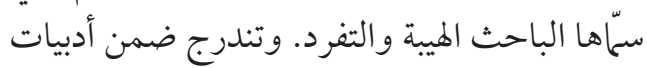

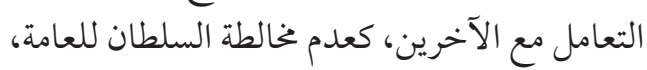

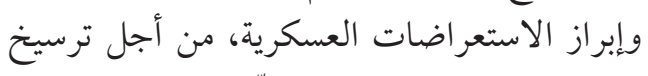

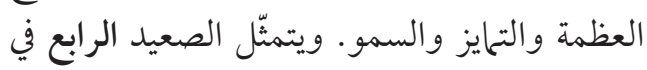

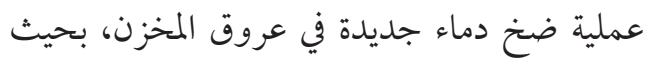
لجأ السلطان إلى المصاهرة، كأوالية (ميكانيزم)

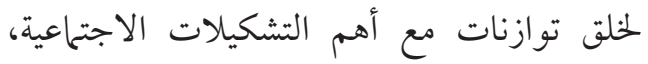
بغرض تقوية القرابة الدموية مع القبائل الحليفة.

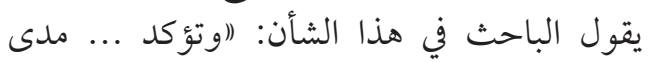

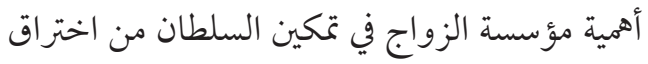

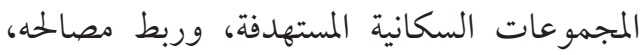

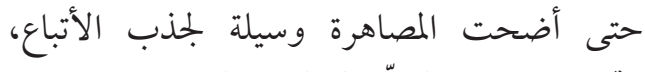
وتخويلهم فرص الترقيّ في السلم الاجتماعي".

وفي حين يوضح الباحث تبعيات الزواج السلطاني

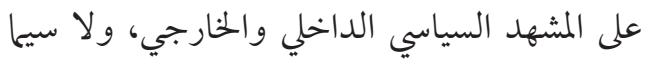

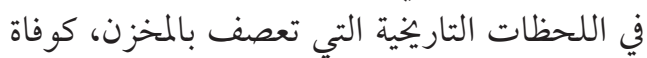
السلطان، حيث أثبتت مشاركة الحريم السلطاني

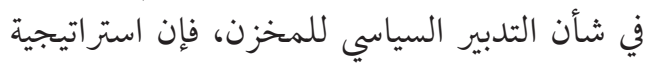
القرابة الدموية تتباين بين السلاطين، نتيجة ظروف لتان الترانيجة تاريخية لكل منهم.

قارن الباحث، في مقاربته للسمات السياسية للملكيات

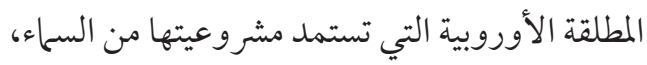

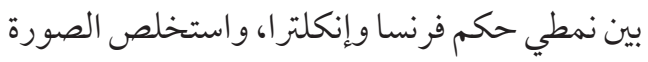

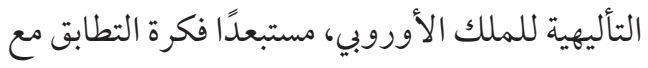

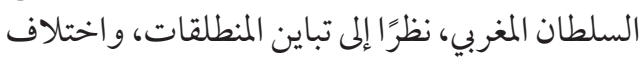

ثم تساءل الباحث عن المفارقة بين الدولة الوطنية

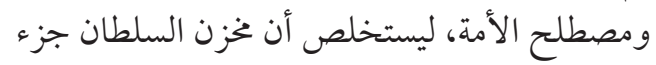

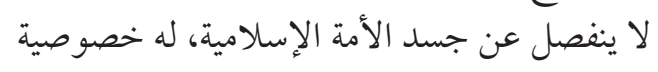

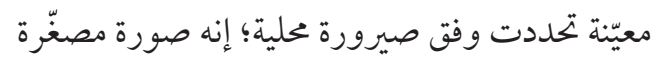

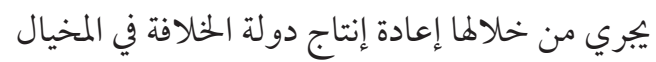
الذهني للشعوب، ولاسيا أن التمثّلات الاجتياعية

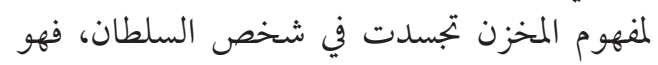

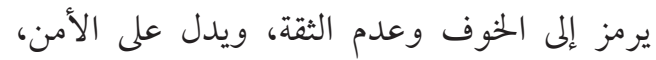
وأخيرًا يؤشر إلى الهيبة والجلاه.

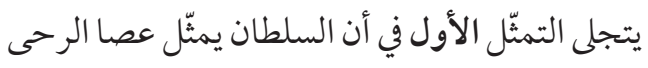

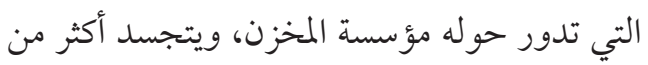

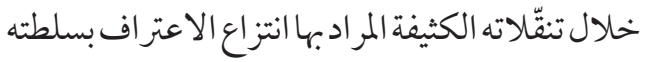

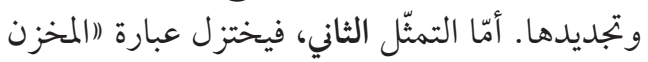

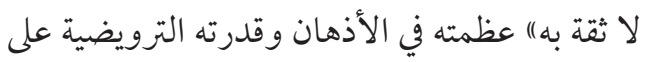

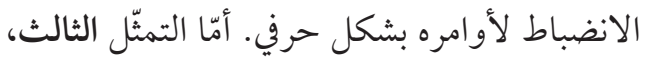

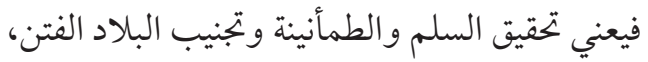

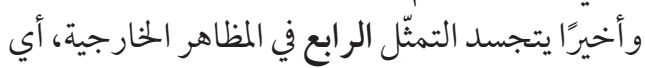
جميع أشكال الاستعر اضات المادية.

\section{المخزن: أسس الحكم|

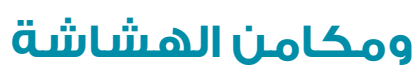

يحاول جادور التعرّف على أساليب ممارسة السلطة في

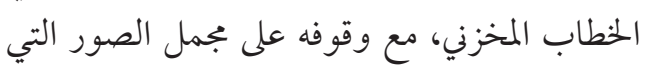

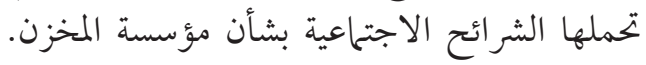

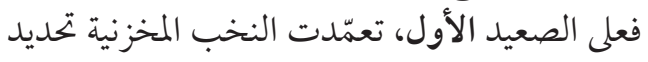

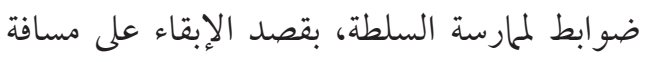

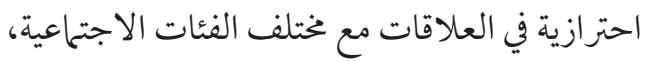

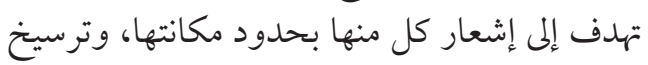
نظام يكرس تعاليه.

و وعلى الصعيد الثاني، يحاول السلطان المغربي اتّباع الحذر الحزي

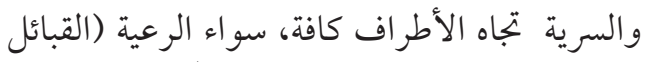

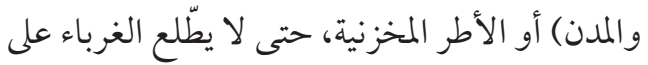

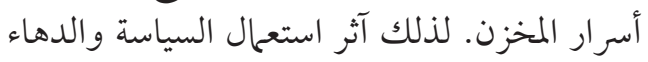


العميم عليهم وتُساهم في تحسين مداخيلهم،

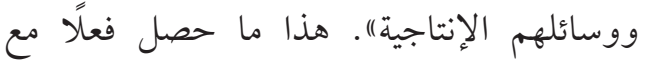

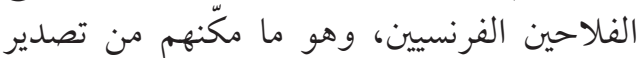

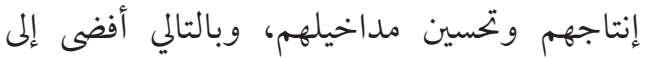
تخفيف وطأة الأزمات عليها.

وسجّل الباحث مسألة هشاشة التقنيات، بالرغم من

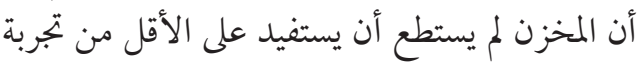

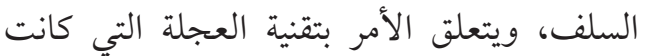

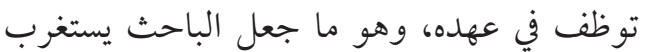
سر اختفائها، من دون الحديث عن قضدهية مسايرة ماتِ

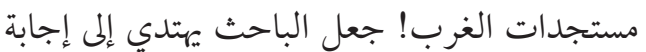

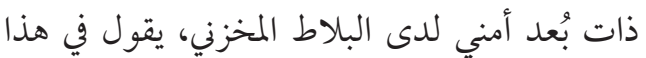

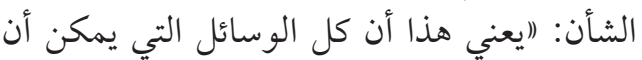

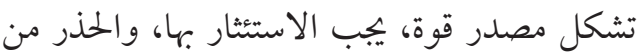
سقوطها في أيدي كل من يتردد في تحقيق التوازن تجاه مؤسسة المخزن، التي لا تطمئن على استمر اريتها ئرديا

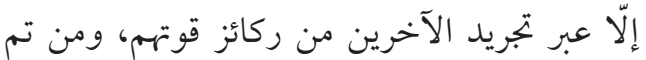

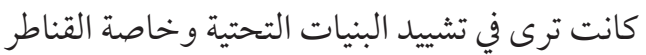

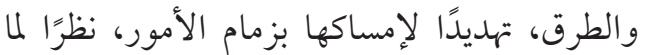
توفره من تسهيلات لتنقل المتمردين والمطلوبين

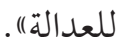

ينضاف إلى السبب السابق (اليد الطولى للمخزن)

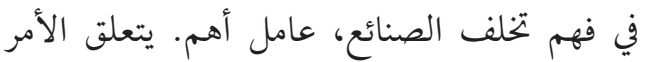

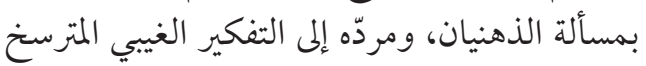

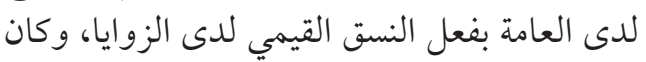

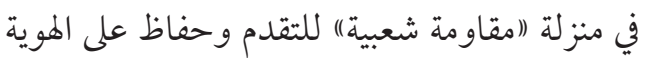

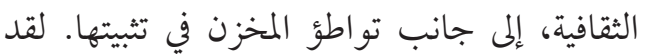
جعل الباحث يصطلح عليها بـاثقافة العادة) التي لئي

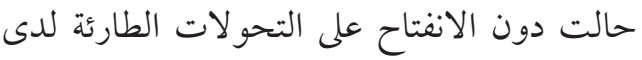

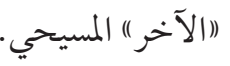

\section{خاتمة}

بعد أن خلخل الباحث ماهية المخزن، حيث دل في البداية على المكان (المستودع) لينتقل إلى عملية جباية إحلية
الظروف التي أفرزت كلَّا منهها، من دون أن يمنع

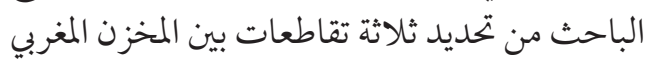
والملكية الأوروبية، على الشكل التالي:

أولًا: غلبة الطابع الاستبدادي على مفهوم السلطة لدى المخزن، كتجسيد للحكى المطلق، يختلط فيه

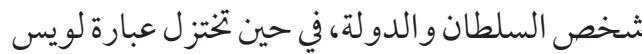
الرابع عشر (أنا الدولة)) مضمون الفكرة السابقة. ثانيًا: توظيف الدِّين في السياسة، فكلٌّ من السلطان

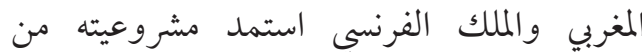

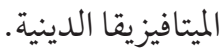
ثالثًا: الطابع الأبوي الذي جسده كلّ من السلطان

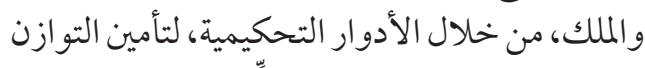
داخل التركيبات الاجتماعية لكلٍ منهـا. وعليه، استنتج الباحث "(وجود قو اسم مشتركة على

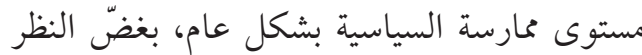

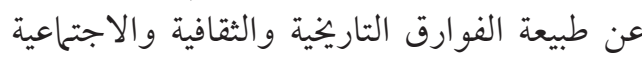

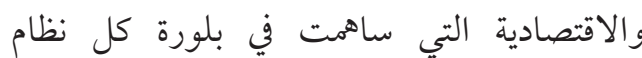
على حدة. بعد أن قارن الباحث بين المخزن وأنهاط الحكىم السياسي في كلٍ من الإمبراطورية العثمانية والملكيات

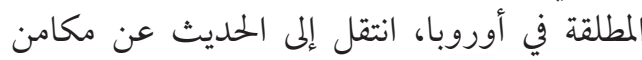

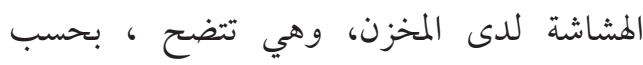

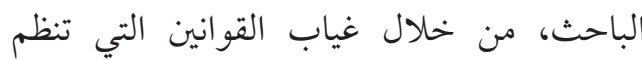

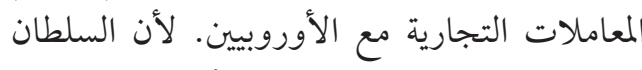

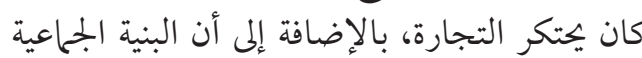

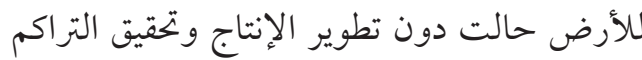

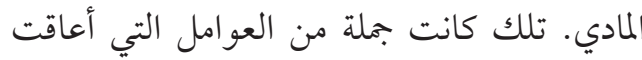
تطور الاقتصاد الزراعي بالمغرب. تمان. يعكس هذا التحليل أن الباحث كان مسكونًا

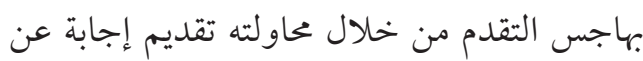

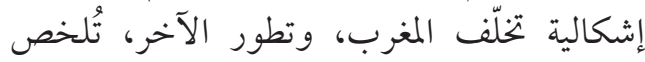

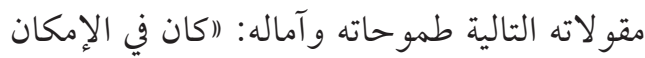
لو تم السماح بتصدير محاصيلها أن تعود بالنفع 


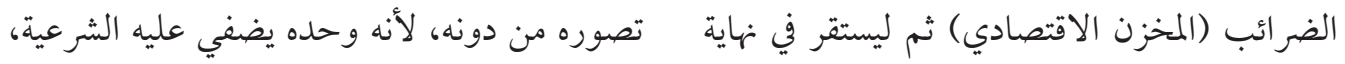

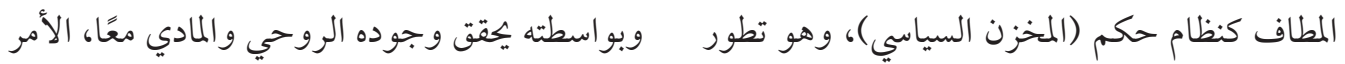

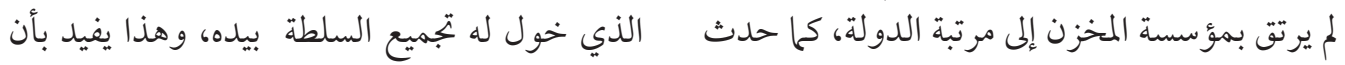

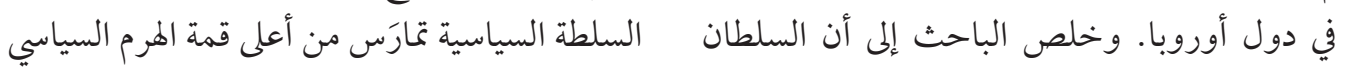

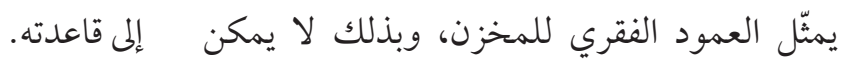

